\title{
THE ROAD TO 2000
}

\section{Molly Levy Lecture delivered by S Inwin-Carruthers}

Minister Venter, Madam President, Madam Chairman, Ladies and Gentlemen -

In 1987 the Council of the South African Society of Physiotherapy bestowed upon Mrs Molly Levy its highest award - that of an eponymous lecture. This was only fitting, because the name of Molly Levy has been synonymous with that of the SASP over several decades during which Molly earned the respect and love of her colleagues both in South Africa and Internationally. It is therefore a great honour for me to stand here today to deliver the second Molly Levy lecture. I would like to thank not only those physiotherapists who nominated me, but also those colleagues and friends at work and at home who have ensured that $I$ have been allowed time to work on SASP projects, I'd like to thank our Chairman - Professor Jo Beenhakker - for her constant support and, last but not least, Molly herself who, in my more youthful days, channelled what I had thought to be rightful indignation into more constructive courses of action.

It is hard to believe that we are in the last decade of the 20th Century. As we look backwards towards the early days of physiotherapy and forwards towards the year 2000 we can see that we are at a watershed in the history of physiotherapy in South Africa. This watershed did not occur mid-century - it was a long, slow haul up to the point at which we find ourselves now, but now we are poised on the verge of a new South Africa with its complex and challenging health needs. Are we top-heavy with our expertise, technology and professional image and liable to fall headlong through the last few years of the century? Or do we have a firm foundation upon which to analyse and solve problems so that, in the year 2000 , we can look back and say that we, as a profession, truly have contributed to the quality of life of our fellow countrymen?

The priorities of the profession over the last decade have been many and varied. They include:

- our first Mission Statement, in 1987

- a strong stance taken against apartheid and all discriminatory practices

- the planned establishment of Divisions for CPE, Research and Publications

- the envisaged Education Foundation and Back Pain Foundation

- and finally, in 1991, the acquisition of our own property.

There is a strong lobby within the SASP which stresses the Society's obligation to meet the needs of its members. This is good, but let us now forget the words of Ruth Wood, currently 2nd Vice-President of the World Confederation for Physical Therapy, when she delivered the 23rd Mary McMillan lecture to the American Physical Association in 1989:

"Physical Therapy is a service profession and as such has no acceptable reason for being except to affect individual needs by the treatment or prevention of disease and disability. Patients are our focus! Without them we are nothing! They are our reason for being!" 1

What has the Society achieved in terms of patient care during these last few years?

Most important, I think, was our Mission Statement of 1987, in which we unequivocally accepted responsibility to strive to ensure quality physiotherapy services to all people of South Africa, to es- chew all forms of discrimination, and to support integration in health care and the provision of a unitary health service. In the same year we conducted a survey into the physiotherapy needs of detainees and published a code of conduct for physiotherapists involved in treating detainees.

Perhaps more obvious to the man in the street in Physiotherapy Back Week - initiated by the Action Committee and now conducted annually at both National and Branch level.More recently the Society adopted a long-overdue policy statement on community physiotherapy. This, and other matters related to the health needs of the land will be debated at the forthcoming Council Meeting.

Whatever the motive for specialisation, standards of patient care will be influenced by the specialisation process which will be initiated at the Inaugural Meeting of the College of Physiotherapists of South Africa, to be held later this week.

Malcolm Peat commented in 1983 that it was generally recognised that it was no longer possible for all physiotherapists to be equally competent in all aspects of clinical practice ${ }^{2}$. Doreen Moore, as early as 1978 , went as far as suggesting that specialisation might begin in the latter part of undergraduate training, since it was not possible to provide undergraduate students with clinical experience in all facets of physiotherapy ${ }^{3}$.

Inasmuch as the accent in specialisation is on clinical competence, its advent is to be welcomed. The establishment of a specialisation procedure gives formal recognition to the process and provides motivation for physiotherapists to improve their expertise in certain areas of patient care. The granting of specialist status enables the public and other health professionals to identify clinical experts, thereby making their skills available to more patients in the surrounding community and even further afield. Identification of areas appropriate for specialisation may identify priority areas in health care and lead to appropriate changes in undergraduate education ${ }^{4}$, but this is not always the case; it may in fact lead to bias in undergraduate and graduate education as well as in the priorities determined by the SASP. We have to ask ourselves whether specialisation and the areas so far identified for specialisation are in harmony with the country's needs for primary health care services and for example, whether they make provision for the projected increase in the number of elderly people by the year 2000 . Are members' special interests perhaps in conflict with the perceived health needs of the majority of the people? It has been observed that increasing specialisation may result in very specific small group interests which may hamper the profession in its working towards overall goals ${ }^{3}$.

It is strange and maybe a sad reflection on our priorities and motives that it has proved more difficult to get a quality assurance programme off the ground than it has been to establish a specialisation process. Nevertheless, we can look back on two years of hard work and enthusiastic participation by so many people from so many parts of the country - two years which have culminated in the beginnings of a national programme. To me this is even more exciting than achieving the reality of specialisation, because quality assurance can only be to the benefit or our patients. It represents the willingness of physiotherapists to evaluate their own performance critically, to acknowledge shortcomings in their service to patients and to seek remedies for these shortcomings in a quest for excellence. Let us never cease to pursue excellence in the performance of our professional acts.

I am convinced that the advent of primary contact has increased our role in health care and has improved our service to the patient. This is only so, however, if we accept our full responsibilities towards the patient. Today's undergraduate students are trained to

- Miss S H Irwin-Carruthers, University of Stellenbosch 


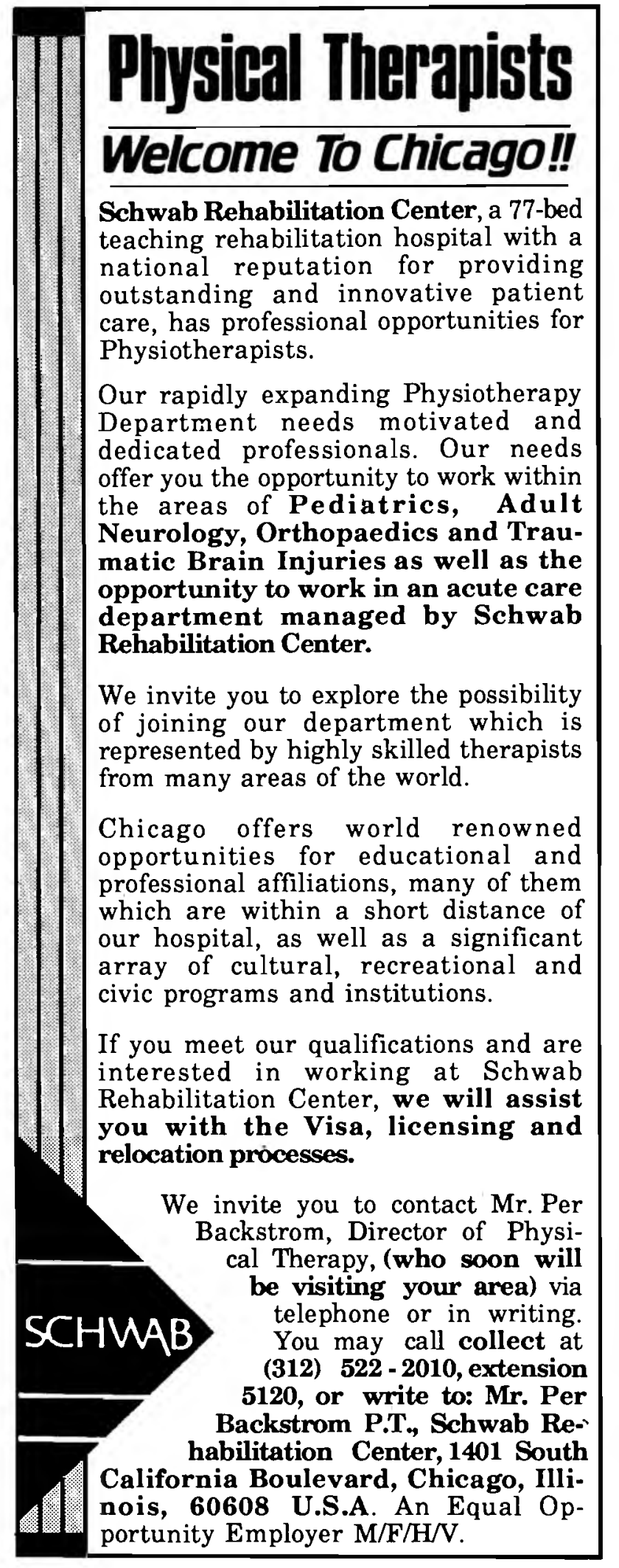

\section{CAMBRIDGE COLLOCATION: EUROPEAN MEDICAL AND PROFESSIONAL RECRUITMENT}

Physiotherapy vacancles in the UK: we have vacancles for physiotheraplsts in the private health sector in the UK. Excellent salarles and working conditions.

Please contact: Maureen Johnston Brown or Margaret Lamb, Cambridge Collocation, 191 Huntingdon Road,

Cambridge CB3 ODL, England.

Telephone: (0)223 276891

Fax: (0) 223276871

Employment Agencies Act 1973 Licence No SE 118181 VAT No 538357911

\section{Curapuls 403}

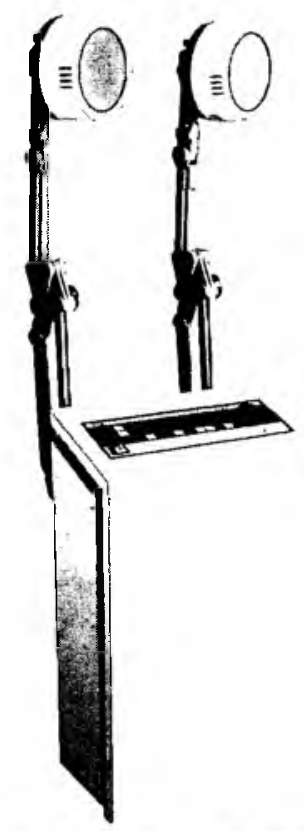

THE NEW STANDARD IN PULSED SHORTWAVE THERAPY

- Compact mobile unit.

- Thermal/Athermal treatments.

- Built-in Microcomputer with selftest.

- 7 Pulse duration steps.

- 10 Pulse frequency steps.

- One or Two Circuplodes - with

simultaneous or independent use.

- Detailed clinical literature provided

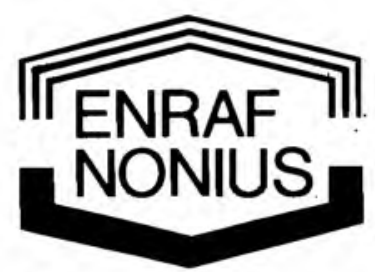

LICENSED BY THE SOUTH AFRICAN RADIATION CONTROL BOARD

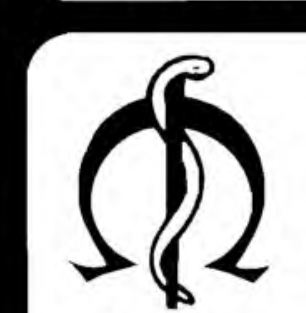

Sandton

Cape Town

Durban

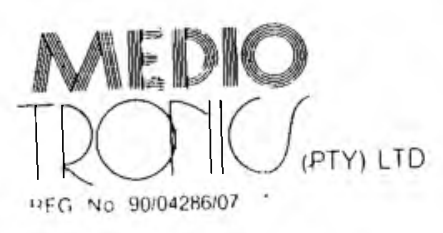

Tel. (011) 803-9320/1

Fax. (011) 803-7085

Tel. (021) 946-4560

Fax. (021) 948-8401

Tel. (031) 561-2798

Fax. (031) 561-4657 
diagnose, to accept those patients who can respond to physiotherapy treatment and to refer to other health professionals those who either cannot benefit or who need additional treatment outside the scope of physiotherapy. Most physiotherapists have proven themselves willing and capable of accepting this responsibility - but why is it so often taken to apply only to private practice? Consider the needs of the country! Why are we not offering our services at primary contact level in local authority clinics and polyclinics? Why are we not looking at community diagnosis in rural and peri-urban areas?

I am saddened that, at an international level, WCPT-Africa has so far not proved equal to the task of combining its resources to the benefit of patients in Africa. The encouraging progress made in Bulawayo in September last year, when so many common problems were identified and when consensus was reached on a Charter for the Region, has been blocked by the inability of two member-organisations to take part in the activities of the Region. To quote again from Ruth Wood" "Before making any decision we must first ask 'What benefits or detriments will the patient derive from this decision?' We must subscribe to the theory that what is good for the patient is good for the physical therapist is good for the Association, and thus is good for the profession. To rearrange that series in a way that puts the physical therapist or the Association before the patient can only invite disaster". Sadly, this appears to be the case.
In conclusion, I am proud and honoured to have been involved in many of the Society's activities over the last decade - in the development of the specialisation and quality assurance programmes, in political statements made in the interests of our patients and colleagues, in the beginnings (however tentative) of WCPT-Africa. I would have been still more proud had we been able to formulate and present to this Congress a long-term physiotherapy health care plan in answer to our country's needs. This is the challenge facing the incoming National Executive Committee. The challenge facing Council this coming weekend is to make quite sure that we, as a professional association, associate ourselves with the emergent new South Africa and with the needs and aspirations of its people.

\section{REFERENCES}

1. Wood R. Twenty-Third Mary McMillan Lecture: Footprints. Phys Ther 1989;69:975-980.

2. Peat M. President's Address, CPA Congress, Winnipeg, Manitoba. Physiocher Canada 1983;35:262-264.

3. Moore DM. Specialisation - professional growth or fragmentation? Physiother Canada 1978;30:249-252.

4. Moore DM. Founders Address, Australian College of Physiotherapists: Fifth Presentation of Fellows, Perth, W. Australia.Austral Jnl Physiother 1985;31:57-60. 